\title{
Urban Food Markets in the Context of a Tourist Attraction - La Boqueria Market in Barcelona, Spain
}

\begin{abstract}
In the last few decades, local governments have looked at developing their cities to increase their attractiveness for tourism consumption. Urban and tourism planners have focused their attention on adapting different local attractions to target the tourist visit and provide them with recreation and entertainment. By consuming locally-sourced traditional or farmed products, tourists adopt the values associated with local identity codes. This experience allows tourists to enjoy the city more as if they were local citizens. In this sense, one method of behaving as a local is to visit a food market. This study investigates the attributes that affect tourist satisfaction in relation to food market visits and explores whether tourists intend to revisit these food halls. Based on a survey relating to La Boqueria, currently one of the most renowned food markets in Barcelona, three factors were identified: physical environment, location and accessibility ${ }_{2}$ and price. The results reveal that physical environment is an important tourist satisfaction predictor, while price and location and accessibility influence revisit behaviour. The results also suggest differences between firsttime visitors and repeat visitors related to attributes perception, while there is no statistically important difference on the path level.
\end{abstract}

Keywords: urban food markets attributes, food halls, urban tourism planning, tourism consumption, sustainable tourism, Barcelona 


\section{Introduction}

Food tourism is a market that has been growing globally in terms of the number of tourists (Richards, 2012). The rise of gastronomic tourism has led to food markets appearing as a new type of resource and tool for the regeneration of urban centres. Also as a cultural attraction, food preparation and consumption contribute to shape local identity (Hashimoto \& Telfer, 2006: 35). As Frisvoll et al (2016:77) state, food products overflow authenticity, sustainability and are an embodiment of cultural, geographic, or rural characteristics. Following this trend, visits to food markets are becoming more popular among tourists. Therefore, such premises are now included in the tourist attraction lists of a destination, especially in urban areas (Pieniak et al., 2009). The food market serves as a commercial and social centre of communities, reflecting local culture and traditions of the people. The specific food market typology referred to in the paper is the sustainable food market, following Crespi-Vallbona and Domínguez-Pérez's classification (2016a). Sustainable markets are attractive resources both for tourism and for provisions for local consumers. This type of food market represents a holistic concept: local food culture, tourism consumption, price, physical environment and history, location and accessibility, resident lifestyle, and food variety. Consequently, tourists find markets to be a reflection of the cultures they want to discover and enjoy during their holiday time (Hjalager, 2002; Richards, 2012).

It should be noted that food markets, as a tourist resource,enable travellers to have new experiences. As Crespi-Vallbona and Domínguez-Pérez (2015) state, food markets are exceptional spaces filled with the history and culture of a territory, tastes and eating habits of the inhabitants of a destination. In the case of most European cities, many of these are located centrally and have historical and architectural beauty and significance. Therefore, when they 
are rejuvenated, they can be a great resource to attract interested tourists. DMOs (Destination Management Organizations) focus their attention on the promotion of local food and culinary experiences from both financial and cultural dimensions, which benefits both hosts and guests (Björk \& Kauppinen-Räisänen, 2014).

A review of relevant literature provides numerous satisfaction studies on gastronomic resources, such as wine and food festivals (Axelsen\& Swan, 2010; Yuan \& Jang, 2007), as well as restaurants (Kim et al., 2009), but there are no studies related to food halls. It is therefore critical to understand tourism consumption and the attributes, which attract visitors to these food centres. Tourists evaluate food markets by considering a range of criteria, such as physical environment, location and accessibility and price. La Boqueria market, with its central Barcelona location, could assist in broadening knowledge of the main attributes that tourists consider regarding their visits to food markets.

As Crespi-Vallbona and Domínguez-Pérez (2016b) note, since the early 1990s, Barcelona City Council has followed a policy of commercial modernization of its urban markets to adapt them to the future challenges related to consumer habits, leisure time and (new) formulas of social relations. In relation to this, in December 2005 the Municipal Institute of Barcelona Markets (IMMB) was founded - configured as an autonomous body under the tutelage of Barcelona City Council - for the direct management and administration of urban markets in relation to approval of ordinances, appointments, creation and demolition of markets and approval of any major works. Thus, the activities of the IMMB focus on three areas: improving infrastructure and services, upgrading the commercial offer and the incorporation of trade promotion policies. In this sense, among the total 43 markets in the city, 19 have already been remodelled and a further ten are at various stages of renovation. In 
addition, the next Strategic Plan of Markets of Barcelona (2015-2025) aims to continue to work with all stakeholders in the distribution chain to define the future of markets in Barcelona.

Therefore, central to the article's interest are factors that change a traveller's perceptions when deciding whether to visit a food market, the key attributes associated with satisfaction and revisit intention towards food halls. Accordingly, the aim of the study is two-fold; first to explore if the attributes of food markets contribute to tourist experience of food markets and to build a traveller behavioural model based on satisfaction and revisit intention; and second, to determine if there is any difference in perception of significant variables and proposed paths between first-time visitors and repeat visitors. Furthermore, the study has various implications, such as providing insight to consider DMO policies related to renovation and promotional activities, tourism consumption proposals and destination branding development.

\section{Demarcating food market interest}

Just as tourism is a global phenomenon, local governments are often involved in the development of activities in their immediate geographic area. Additionally, in places where tourism is perceived to be an important element of the local economy, the government may engage to manage, implement, control and improve tourism in the area. This engagement depends on local political priorities, the degree of importance of tourism to the economy of the destination and the views of local residents. The governance and tourism policies of different local organizations in Barcelona are mainly led by a sustainable strategy. Local planning and policy functions are designed to achieve longer-term goals, focusing on a combination of controlling and stimulating development to create lasting benefits, such as the improvement of local people's lives and the distribution of profit to both direct and indirect 
tourism business. This is particularly applicable to mature tourist destinations such as Barcelona, where the City Strategic Plan (Pla Estratègic de la Ciutat, 2020) seeks to create tourism sustainability by encouraging local resident participation in its design and proposals.

In this context, local governments own and operate local resources that attract tourists, such as parks, museums, art galleries (Hall, 1995) and finally, food markets. This expansion of new tourist resource options follows the logic of leisure outskirts (Blázquez, 2011), not only in the geographical sense, but also in a wide range of attractive icons. As many scholars state (Glaeser et al., 2001; Florida, 2009; Navarro et al., 2012) the novelty in current urban planning is its dependence on cultural consumption. This cultural consumption in turn leads to the implicit tourism, entertainment and leisure model. Indeed, specific cities are attractive to the visitor due to the perception of the lifestyles led in them.

Consequently, this tourism process modifies the cultural and social environment where it operates by different ways: creating businesses, changing landscapes, demarcating policies, organizing and disorganizing social configurations (Delgado, 2007). In this context, governments have a notable challenge to find a balance between considering tourism activity and local residents. This purpose of sustainability focuses on finding a degree of satisfactory compatibility for both the needs of local residents and visitors to avoid hostility or confrontation between both groups. This is the starting point in the analysis of food markets. As Hiebert et al (2015: 8-9) argue, markets exist in all shapes and sizes including: night markets, farmers' markets, urban street markets, open air markets and indoor food markets, all of which are often in historical buildings or areas. Nowadays, indoor food markets in urban areas fall into different categories. Markets that survive and prosper are often located centrally or in surrounding areas and are those that have high potential for tourist visits. In 
some cases, they have been converted into gourmet markets or other types where people can eat, relax and savour the atmosphere whilst sometimes inadvertently participating in cultural shows with gastronomic character (Food Halls or Show-cooking). Therefore, CrespiVallbona and Domínguez-Pérez (2016a) establish a typology of food markets located in historic and tourist centres: touristified markets (designed, remodelled and restructured purely according to tourist demand), sustainable markets (traditional food markets that are attractive to tourists while retaining their traditional and local customers, allowing them to realise a balance between attractiveness and sustainability), and traditional markets (undergoing a process of transformation with an unclear or uncertain future). In essence, as some scholars argue (Sims, 2009; Okumus et al., 2013), local food, and also food markets, can be used for differentiation in the context of marketing activities and as a key resource in the process of sustainable tourism development.

This food market evolution involves the disappearance of tourist and resident duality and the settings of a vast range of "urban users", where tourism is really integrated into the city. This integration is a result of cities becoming "experimental places" (Barrado Timon, 2010), where local expertise is required. It is therefore necessary to consider another aspect to the cultural tourism experience. As Richards states (2007:2): “in the past, cultural tourism was largely associated with high culture and with "cultured" people". Today, cultural tourism includes everyday life of local communities. Resources associated with cultural tourism have expanded from the largely fixed, tangible heritage of the past towards mobile, intangible contemporary culture. Indeed, the aspect of "local" is automatically linked to "authentic" and a key element for the tourism industry (Taylor, 2001, p. 7), taking consideration what "local" really means. Consequently, DMOs need to consider economic stakeholders as well as the "host society” (Ávila \& Barrado, 2005, p. 30-31). Hence, in the specific case of local 
markets, tourists look to discover the uniqueness and authenticity of local food markets as a key value of the particular culture and way of life of the destination (Smith and Costello, 2009). As a result, these food markets become one of the resources and exponents of a brand new city. That is, spaces recognized for their ability to attract new experiences, where tourists can mix with the local population as they go about their daily lives. This is the primary attraction for the new food or gastronomic tourist generation.

Tourism consumption must be planned in a sustainable manner. In 1994, Elkington (1994) proposes three sustainable dimensions - the "triple bottom line", which includes financial, social and environmental performance measures. Urban planners, as well as tourism managers and those responsible for food hall development, need to be aware of and analyse the attributes that attract and motivate tourists in their decisions to visit food markets. Subsequently, Liu (2003) or Paddin (2012) added the need to include residents and tourist necessities, in the present and in the future. In 2013, the European Commission added a new dimension - destination management. Therefore, this paper focuses on this last central dimension and conducts some research into the satisfactory aspects of visitor management of tourist attractions - which of course, food markets are.

\section{Physical environment of the space}

Markets are good places for interaction. They help to develop a sense of community pride and ownership. The people who use and visit them can start to see them as centres of belonging and of the community. Therefore, these places or buildings are normally planned and designed as a result of their use. Physical barriers tend to be eliminated, because stall design needs to maximize interaction with the customer. There are four characteristics of 
places that assist interaction: they provide reasons for people to go there, reasons to stay, a feeling of safety and comfort, they are welcoming and accessible. All of these are largely dependent on design.

There are also different conditions that make a certain space accessible and welcoming. For example: a visible and welcoming entrance; high cleanliness standards within the main hall; access for the disabled - including ramps and even surfaces; and clean and accessible toilet facilities.

Additionally, it should be highlighted that customers feel less inclined to frequent a location if they do not feel safe, or if it is dirty, dark, damp, cold or full of loud and unpleasant noise, or vandalized. According to numerous pieces of research historical and traditional appearance, cleanliness, accessibility, safety and light/brightness are all factors that influence tourists when choosing to visit restaurants, food festivals and other food experiences (Kim et al. 2009; Yuan \& Jang, 2007; Lee et al., 2008).

\section{Location and accessibility}

Until the 20th century, villages, towns and cities had a number of meeting places. Social life often centred close to such establishments as a marketplace, the church, the courthouse, a public house, the post office, the town hall or the train station. Tourists enjoy visiting places that bring local people together and see them mix naturally. They are often located in the historic centres, are easy to get to and find and are also close to the main tourist attractions of the city. Hence, as Wan and Chan (2013) argue, location and accessibility are factors that satisfy travellers in their food experiences. People like to be able to easily find food markets 
and feel welcome when they arrive. Signage in a variety of languages aids tourists in finding the markets and often when they are central, they can be easily reached on foot or via use of public transportation.

\section{Price}

As Steptoe et al. (1995) state the main interest to choice and buy in food markets are good quality items, good value for money, variety and inexpensive options. These factors remain important in people's daily buying and eating habits and it is likely that they will be adopted when they travel. "Quality" is a term often associated with local and organic food. It is known that local and organic food has been identified as a means to increase trust in the food that people eat. Despite tourists, as well as residents, considering that high prices in local foods are justified, the "local is more expensive" assumption is flawed (Donaher, 2012). Donaher argues in a study in Ontario, Canada that there is no evidence that local Ontario products are consistently higher in price than their non-local, non-Ontario sourced counterparts. Therefore some assertions that local food is an elitist domain or "too expensive" are eroded. However, there has been little discussion concerning the perceived strong relationship between price, product and attributes.

\section{Satisfaction and Revisit Intention}

With regards to satisfaction, many scholars argue that tourists with previous travel experience are more likely to return to those destinations known for offering outstanding overall satisfaction and perceived value. Gastronomic experiences play an important role in satisfaction with a travel experience and shape future travel behaviour (Nield et al., 
2000).Therefore, food markets with a favourable level of routine, cultural places, prestige, authenticity and uniqueness project a positive image and induce memorable experiences in their food halls. All of these dimensions combine to form a tourist's aesthetic judgment, with special emphasis on satisfaction, revisit intention and the intention to recommend the place that was visited to others (Kirillova, 2014).

\section{Difference between first time visitors and repeat ones}

As Kim et al. (2010) state, many scholars have proved that tourists with prior experience of travel have a higher level of intention to travel again to those destinations known to them. In McGinnis' words (1968, as cited in Petrick, 2004, p.29), repeat visitors have a "cumulative inertia" and they have a tendency to buy more products or services than new consumers. Returnees are experienced travellers and they repeat their vacation experience whenever the satisfaction and perceived value are great, important and unique. They have the tendency to repeat visit because it is less risky, closer and known in addition to feeling safer and more confidence. These assumptions have been proved as Kim et al. (2010) demonstrate that food tourists also are more likely to return to a destination previously visited.

\section{Methodology}

The Boqueria food market located in Barcelona, Spain, is the illustrative case used to investigate the tourist satisfaction attributes and to identify the argumentative factors for managing a tourist attraction. For the study, a quantitative research approach was chosen. It makes use of statistical methods to link food market attributes as a motive for satisfaction and 
revisit intention of these food halls. Question items were absorbed from existing research and adapted to food markets characteristics.

\section{Context of the study}

The research was conducted on La Boqueria food market, one of the most famous tourist attractions of Barcelona. La Boqueria Food Market is listed as one of the "must-visit" locations in the city. Barcelona is one of the few cities in the world that has a network of markets in every one of its neighbourhoods. As a result, city-wide there are 39 food markets and four non-food markets (43 in total) which are under IMMB's management, the independent public agent of the City Council.

During the last two decades of the twentieth century, Barcelona's traditional markets suffered a severe decline. Several issues were the cause including: little public investment; a sudden and significant change in the buying habits of the population; the incorporation of women into working life; the emergence of shopping malls and supermarkets; the process of urban sprawl of the population to the wider suburbs; and trade liberalization schedules. However, nowadays, food markets located in the historic centre of the city or the surrounding areas are thriving due to tourism demand. They have been restored and extended with modern facilities and services (home delivery, online shopping, customer car parks, wireless internet access, self-service areas, leisure activities, workshops and educational programs, specialized supply and fresh goods) and have been adapted to the both demands of citizens and tourist users alike (Crespi-Vallbona and Domínguez-Pérez, 2016a). 
In the historic and tourist centre of Barcelona, there are four food markets: La Boqueria; Santa Caterina; La Barceloneta; and Sant Antoni. According to the food market classification done by Crespi-Vallbona and Domínguez-Pérez (2016a), the former three are "Sustainable Markets", as they combine ancient customs with contemporary tourist customs. Tourism guarantees the survival of most of these three, but the coexistence of these local and tourist users is not always peaceful. Therefore, if the flow of tourists is not monitored, these food markets risk moving towards 'touristification' - this is primarily the case with La Boqueria. The latter market, Sant Antoni, is undergoing a clear process of touristification. It maintains its traditional character - offering quality products, supplying goods to local residents and neighborhoods, but as it is located in a new area of tourism spread, consequently some establishments have already started the process of tourist conversion. In fact, by the end of 2017 it is expected that its historic Art-Nouveau building, now under remodeling, will be reopened. The hope is that its traditional function will work in harmony with its newfound tourist function (Figure 1).

\section{Insert Figure 1. Barcelona inner city markets}

\section{Source: Prepared by authors in the QGIS 2.6 software package using Openstreetmap}

\section{(OCM) layer or Google Map}

In essence, the value of La Boqueria comes from its antiquity - it was a meeting place in the twelfth century and the current building was constructed in the nineteenth century, before being remodelled in 2000. Furthermore, it promotes its locally-sourced goods, which reflect the authenticity and uniqueness of the space. The market consists of 250 stalls that offer both traditional products and delicatessens. It is also important to note its location - next to the thoroughfare Les Rambles, in the heart of the historic centre of Barcelona and its proximity to 
the main attractions of the city, such as the Cathedral, the City Council, the Palau de la Generalitat, the Liceu and the Colon Statue (Figure 2).

\section{Insert Figure 2. Location of La Boqueria market in Barcelona city center}

\section{Source: Used with permission}

As the main entrance is located on Les Rambles, it follows that the first two vertical aisles and also the spacious, horizontal central aisle, which are closest to it, are those that have the highest tourist footfall. Immigrants run a significant number of stalls and the majority of them focus on produce that meets the needs of tourists, such as fresh fruit juices, ready-prepared and cut fruit, ready meals, confectionery and other take away items. This is a consequence of various websites and tourist guides that have declared La Boqueria an unmissable attraction when visiting the city. However, La Boqueria also supports traditional stalls selling produce such as meat, fish and other fresh groceries of renowned good quality. These stalls are located on the aisles that lie near to Gardunya Square and generally are prone to less tourist pressure and seen as the area used by locals (Figure 3 ).

\section{Insert Figure 3 and 4. Photos of Boqueria market}

\section{Source: Taken by author}

Due to the high influx of visitors, daily purchases can prove difficult or uncomfortable for local people. As a result of this, some demonstrations were staged in winter and spring 2015, which led to urgent local political intervention. To ensure social coexistence between local and tourist visitors, the local government approved a decree limiting visits by organized groups of tourists (of 15 people or more) on Fridays and Saturdays from opening to 15:00 
hours, to protect the use of this space for residents, encouraging the proper development of market activity to avoiding building collapses within the enclosure (Regulation of access to the site of the Municipal market St. Josep / La Boqueria, April 2, 2015). A new regulation, passed in February 2017, will restructure the inner space of the halls, requiring some stalls to widen the halls and relieve the pressure on them (IMMB, 2017). Therefore, the layout of the halls in the food market will be different by the end of 2017 . The desire is for people to be able to browse and purchase more comfortably (Figure 5).

\section{Insert Figure 5. Map of the Inner Boqueria}

\section{Source: Used with permission}

Related to leisure activities, cooking classes for adults and children as well as gastronomic events are organised and the opening hours have been extended until 21:00 hours from Monday to Saturday. Its Monday, a day when many of traditional establishments are closed, constitutes its third best day in terms of sales, behind only Friday and Saturday. The image projected from its website is a colourful, cheerful, neat and functional one that promises the consumer all varieties of products which follow the principles of sustainability, according to the Strategic Plan of Tourism of the City 2015. Furthermore, La Boqueria participates in the URBACT project - in conjunction with another nine cities across Europe. The aim of the project is to provide action-orientated knowledge about how urban marketplaces can be used to develop low carbon, local supply chains, as well as better and more sustainable urban planning, employment and entrepreneurship (http://urbact.eu/urbact-markets).

\section{Design of the sample}


The research was conducted in order to identify the key attributes of food markets as tourist attractions perceived by tourists. The questionnaire included variables that measured attributes, which are important for the development of tourism in the food markets: the physical environment, location and accessibility and price. The research model (Figure 6) that was used for the realization of empirical research includes five variables: physical environment, location and accessibility, price, satisfaction and revisit intention. Independent variables are the physical environment, location and accessibility, and price while dependent variables are satisfaction and revisit intention.

\section{Insert Figure 6}

In order to ensure that the questionnaire was straightforward for respondents, it consisted of a single printed page. After the questionnaire was constructed, it was pre-tested on a small sample of 20 randomly selected respondents. The results of this pilot survey suggested that the statements in the questionnaire were clear and easy to understand and there was no need for additional changes. The survey questions were asked to visitors at the main entrance to La Boqueria food market and throughout the market. The information was collected on Mondays (a day of lower tourist footfall) and Fridays (a high number of tourists) at different hours of the morning and afternoon, between the dates of 9th March and 17th April 2016. During data collection, particular attention was given to ensure that respondents were tourists and not locals. A self-administered questionnaire was selected as it has a high level of accuracy, limited cost and responses remain anonymous (Malhotra, 2004). Respondents who agreed to participate in the study were provided with sufficient time to consider their responses. A total of 210 questionnaires were collected, 200 of which were completed as instructed, while the remaining ten questionnaires were excluded from further analysis due to being incomplete. 
The research was conducted on a convenience sample of 200. During questionnaire formulation, it was decided that the sample should cover an approximately equal number of men and women with different educational levels and different occupations, whose ages range from 18 to 70 years (Table 1$)$.

\section{Insert Table 1.}

\section{Measures}

The factors used in the distributed questionnaire were chosen through a review of relevant literature. The physical environment was measured by two items, which were selected on the basis of study by Lee et al. (2008). The location and accessibility element was measured by two statements, which were selected on the basis of studies by Wan and Chan (2013). Two items were used to measure the relationship between tourists and price and were designed on the basis of study by Steptoe et al. (1995). Satisfaction, as dependent variable, was measured with four statements on the basis of studies by Mason and Paggiaro (2012), while revisit intention was measured with three items. All items were additionally adjusted for the purposes of the study. All statements were measured on a seven-point Likert scale (1-I fully disagree, 7- I strongly agree).

\section{Data analysis}

Data analysis was performed through the Statistical Package for Social Sciences (version 21.0) and AMOS (version 18.0). Next, statistical analyses were undertaken: reliability analysis, correlation analysis, confirmative factor analysis (CFA), structural equation 
modelling (SEM), and t-test. In the first step, values of the coefficient Cronbach's alpha were estimated in order to test reliability and internal consistency of the latent variables. Then, by means of the confirmative factor analysis, the fit of the research model was tested. Structural equation modelling (SEM) was then used to examine the relationship between independent and dependent variables. T-test was used to determine if there was a statistically significant difference concerning the perception of variables between first-time visitors and returnees. Finally, multigroup SEM was deployed to examine if there was difference in the model paths coefficient, comparing each group separately.

\section{Results}

Based on the value of the Cronbach alpha coefficient, the reliability and internal consistency of the statements used to measure the latent variable models was estimated (Table 2). All variables had an adequate level of reliability, as the coefficient of Cronbach's alpha was over the required threshold 0.6 (Hair et al., 2006). The results showed that the highest degree of reliability was expressed within the revisit intention variable (Cronbach's alpha $=0.906)$, while the location and accessibility variable presented the lowest level of internal consistency of the statements for its measurement (Cronbach's alpha $=0.644)$.

The condition of convergent validity was met by the fact that the AVE of all constructions was greater than the minimal threshold of 0.5 (Fornell \& Larcker, 1981). Through comparison of AVE and squared correlations between constructs, discriminant validity was also analysed. Given that the value of AVE for each individual construct was greater than the squared correlations between the given construct and other constructs, discriminatory validity 
was assured for the model variables. Composite reliabilities (CR) of all variables were above the required minimum of 0.6 (Table 2 ).

\section{Insert Table 2.}

In the second step of the analysis, the consistency of the research model, which was developed using the confirmative factor analysis, was tested. In particular, the values of the following indices were calculated: $\chi^{2} / \mathrm{df}, \mathrm{CFI}$, GFI, TLI, IFI, RMSE. The values obtained are shown in Table 3. From the table it can be seen that the values of all the indices observed exceeds the minimum thresholds required for creating harmonious models. Relationship $\chi^{2} /$ df is less than 3, the value of the GFI, CFI, TLI and IFI indices exceed the threshold of 0.9 (Byrne, 1998), while the value of the RMSEA coefficient is lower than the threshold of 0.1 (Steiger, 1990). Due to the fact that the results confirmed the validity of the appropriate test model, in the second step of the analysis, attention was focused on observing the relationship between the latent variables.

\section{Insert Table 3.}

In order to test the influence of the independent variables on the dependent (satisfaction and revisit intention), SEM was used. The effects of the physical environment, location and accessibility, and price on satisfaction and revisit intention were observed.

As the results suggest, only the physical environment variable showed a statistically significant effect on satisfaction $(\beta=0.196, p>0.1)$. The above research findings indicated that visitors believe that physical attributes, such as cleanliness and accessibility of the site, 
are determining aspects for satisfaction related to La Boqueria food market visitation, which is expected given the fact that the market is a very popular tourist attraction, so the site environment must be organised based on tourist demands and adapted for their use. On the other hand, the location and accessibility and price variables were not factors that significantly affect the satisfaction of visitors (Table 4).

\section{Insert Table 4.}

When revisit intention is considered, the price variable $(\beta=0.262, p<0.05)$ and the location and accessibility variable $(\beta=-0.321, \mathrm{p}<0.05)$ showed a statistically significant effect. On the other hand, the results of the research did not confirm a significant effect of physical environment on revisit intention. Interestingly, tourists perceived physical environment as an important variable for the satisfaction level of their visit, while it is not important for revisit intention. Location and accessibility had a statistically significant effect when revisit intention is the issue, with the negative value of its impact indicating that the location and accessibility of La Boqueria, which is in the city centre, is a disincentive for tourist revisit intention, as they seek a new tourist experience in other "undiscovered" parts of Barcelona during their revisit journeys. Also, it is interesting that the prices in the food market do not affect satisfaction with the visit, yet tourists found it was very important when it came to revisit intention. La Boqueria is considered a must-see tourist attraction, so tourists do not correlate the pleasurable experience of visiting it with the prices in the market, especially during the first visit - yet this is not the case when it comes to revisit visitation. There was also a positive relationship between satisfaction and revisit intention $(\beta=0.883, p>0.01)$, suggesting that if tourists were satisfied they were likely to visit the market again (Table 5). 


\section{Insert Table 5.}

Once the factors that are important to tourist satisfaction and revisit intention for La Boqueria market visitation were determined, it was examined whether a statistically significant difference in the perception of significant variables, among visitors who are first-timers and returnees could be determined.

Sample consisted of 200 respondents, comprised of first-timers (128) and return visitors (72), in order to determine statistical significant difference regarding attributes, $t$ test was applied. The analysis has shown statistically significant differences in the attitudes of first-time and return visitors concerning physical environment at a level of significance of 0.05 , while price and location and accessibility were found to be significant at a level of 0.1 (Table 6).

\section{Insert Table 6.}

The analysis of the physical environment difference for first-time and return visitors revealed that first-time visitors perceive cleanliness and accessibility as a more important attribute in comparison with return visitors. It suggests that returnees were more orientated towards other particulars, since they were more familiar with the site. The analysis of price as a variable indicated that first-timers consider price more important, while for return visitors, price is less important as they are more familiar with the destination, meaning they can easily find more affordable prices at the site or at other food markets. The analysis of the location and accessibility difference suggested that first-timers perceive location and accessibility as more important in comparison to repeat visitors, which is to be expected given that first-timers would tend to have high expectations regarding location and accessibility, which enables 
them to find the market much more easily, while returnees are more familiar with the destination, decreasing the importance of this aspect.

Since t-test has revealed that there were evident differences in attributes perception between first-time and returning visitors of La Boqueria food market, it was worthwhile ascertaining if these differences were noticeable also on path level. Therefore a multigroup SEM analysis was conducted, testing if there was difference in the model paths coefficient for each group separately.

The results indicated that the groups were not different on the path level, although t-test suggested difference regarding variables. However, few differences in comparison to the original model have appeared. In the case of the first-time visitors, the results were similar to the results of the total sample, the only difference being that the relationship between physical environment and satisfaction for first-time visitors was not significant. The results for repeat visitors showed that only physical environment achieved a statistically significant association with satisfaction, while there was no significant determinant of revisit intention for returners. From the results, nevertheless it was clear that there is difference between first timers and repeat visitors regarding attributes relationship between attributes and satisfaction and revisit intention is shown as statistically insignificant. Therefore, results suggest that differences need to be investigated more thoroughly in order to provide material for organizations responsible for tourism development in their future marketing activities (Table 7).

\section{Insert Table 7.}




\section{Discussion and implications}

\section{Theoretical implications}

Nowadays, urban food markets are no longer merely a place where locals buy food for their daily needs. Over time they have become important tourist attractions and therefore places of intense and considerable tourism consumption. Food markets as tourist attraction connect visitors, residents, and the local food and culture (Silkes, 2012). Due to their specific, social environment with intense live interaction between visitors and the local population, they can also be perceived as a small-scale food festival (Silkes, 2012).

La Boqueria food market truly reflects resident life and culture, but simultaneously the sheer level of tourist presence is the cause of some degree of hostility between the local community and tourists. Some demonstrations in the halls of La Boqueria (2016) and local press articles (La Vanguardia 2016, 2017) reflect the levels of tension and strain that are present. The rising discrepancy between the demands of local people and tourist visitors requires urgent urban planning or structural revision. Such actions must address the needs of the local population but in such a way that they do not cause delays in or barriers to the benefits that can be realised from tourism development. Additionally, the important attributes that attract tourists must be identified in order to find an appropriate way to maximise their potential. Certainly, any high priority revision or restructuring of the planning and management of these food halls needs to be based on the main principles of sustainability and finding a compromise between both uses and users. 
The study also contributes considerably to the existing literature by identifying the key triggers of satisfaction and revisit intentions for food market visitation, focusing on market attributes, an approach that has seldom previously been used in studies concerning food tourism (Silkes, 2012). The originality of the study is also due to the difference in perception of first-timers and return visitors, concerning the important attributes of food markets and their paths, which enriches the theoretical background.

Physical environment is identified as an important satisfaction antecedent, which is consistent with the results obtained by Silkes (2012) in his research of food markets, or Mason and Paggiaro (2012) and Lee et al. (2008) in the setting of the food festival. The results suggest that location and accessibility is seen as an unimportant factor that influences visitor satisfaction, which is also consistent with the findings of a study about food markets by Silkes (2012), where location is present as an item in a variable shopping experience. Yet, the result obtained is inconsistent with results in several studies that were primarily focused on food events (Wan \& Chan, 2013; Wu et al., 2014). Urban and tourism planners have to pay special attention to the physical environment, as the tourism experience is highly dependent on it. In order to expand tourism to new areas of the city and facilitate new flows of people to manage the concentration and the overcrowding in central and historic parts, surroundings are a highly relevant determinant to success in the product lifecycle sense (Collins-Kreiner, 2016).

While price is considered as unimportant for food market satisfaction, it is still important for revisit intention, mirroring the results obtained in studies that observed the relationship between total tourism expenditure and revisit intention (Kim et al., 2011). Physical environment is shown as insignificant for revisit intention, supporting the results gained in 
Silkes' (2012) research. The results also imply that satisfaction has a significant influence on revisit intention, again confirming the connection between satisfaction and revisit intention which was highlighted in other earlier studies for different tourism products (Lee et al., 2008; Mason \& Paggiaro, 2012; Wu et al., 2014; Silkes, 2012, Ozturk \& Gogtas, 2016).

As limited research has been conducted in an attempt to reveal the differences in travel behaviour between first-timers and repeaters in food tourism (Kim et al., 2010), this study attempts to broaden the understanding of this topic. Perceptions of physical environment, price and location and accessibility among first timers and return visitors of La Boqueria food market showed statistically significant differences. The analysis of price as a variable, showed that first-timers perceive price as more important, a relationship which is not present when observing the attitudes of return visitors. This is also confirmed in results obtained by Kim et al. (2010), who concluded that repeaters are already familiar with the destination and know exactly where to go and where to spend their money. However, nevertheless that few changes in comparison to original model exist, results suggest that there are no differences on the path level between first time and return visitors.

\section{Managerial implications}

Individuals and organizations that are responsible for the tourist development of food markets must pay particular attention to the physical environment. Focusing on the inside of the food market, the overcrowded main corridors are a critical issue to address for managers. The Boqueria is located in a historical building which must be preserved. Therefore, sustainable strategic management has to drive reforms to readapt the current stall structure. One option would see the removal of some stalls and their conversion into small squares or open areas in 
the inner food market. These new empty spaces would help and facilitate the tourist visit as well as the purchases made by residents. Another aspect related to the physical environment is the cleanliness and ready accessibility of the site. This must be a priority for management of food markets, especially in increasing the number of toilet facilities and ensuring continuous efforts to maintain the cleanliness and hygiene of the whole market.

The surrounding area of the market has recently been remodelled. An underground parking facility and the consequent Gardunya open square are both the result of the IMMB plan to recuperate and modernize the Barcelona food markets (Crespi-Vallbona and DomínguezPérez, 2016a). The parking area provides better access and service to stallholders and also local customers. The Gardunya square has become a place for tourists to relax, eat and reflect on their visit to the Boqueria. It is also assists in flexibly managing the market's capacity level - ensuring it can accommodate the optimum level of visitors.

In the case of the Boqueria revisit intention, its location and accessibility have been identified as important factors, but as a disincentive for repeat-tourists, as they seek out a new tourist experience in other "undiscovered" parts of Barcelona, perhaps another smaller food market that is less populated by tourists. Its location in the heart of the historic centre of the city and just off Las Ramblas, the main pedestrianized avenue of Barcelona, makes this tourist resource well located and easily accessible - a fact that is more important for first-time visitors than those repeating their visit. Hence, for first-time visitors, the Destination Management Organization (DMO) - in this case, the IMMB - could look to develop a mobile application to improve accessibility to the site or look to install additional tourist signage, which may assist in increasing the number of visits, especially of foreign tourists, but also redistribute them more equally through the market's eight entrances. Marking lateral 
entrances would surely reduce the number of people entering the market via its main entrance and consequently, reduce congestion within the main corridor.

For tourists with a revisit intention, price is also an important factor, so although La Boqueria is now a famous tourist site, prices must be reasonable, or the number of those people returning will continually fall over the years. This is apparent in the expressed view of return visitors, who compared to first-time visitors, were of the opinion that prices were high and were dissatisfied with the level of value for money. Thus, stallholders need to deliver food products with consistent quality to reap the long-term benefits, which can be achieved particularly through the branding of food products. Kim et al. (2010) discovered that repeat visitors spent more money than first-timers on a daily basis. Adding more reasonably priced, quality products would provide benefits for both stallholders and visitors alike. While firsttime visitors are more interested in improvements in accessibility and price, return visitors are more influenced by the physical environment. Therefore, the market's management team must prioritise facility management, through improving the level of cleanliness of the market site itself and any on-site toilet facilities. As the results suggest, satisfied tourists are more likely to revisit a food market, so it follows that DMO should put their efforts not only into attracting new tourists, but also into ensuring long-term benefits for return visitors. In that sense, as Bauder and Freytag (2016) suggest, it could also be interesting to differentiate and encourage well-prepared visits, in order to draw a mobility pattern in the food market. It would help to avoid the effects of overcrowding and lead to a de-concentration of visitor activities. The study could also assist stakeholders who are interested in the sustainable development of food market tourism to broaden their knowledge of visitor behaviour and thus organize marketing activities that fulfil the needs and desires of this segment. 


\section{Future research and limitations}

There are a number of limitations within the research. The methodological limitations of the study were the consequence of the fact that the results cannot be automatically generalized, as every food market offers locally produced food and local culture, thus they are locally and regionally branded. As a result, there is a necessity for similar studies to be conducted across the world.

The modelling process started from the basic model, which is based on the fundamental attributes of the food market, but in future research it would be advisable to test an advanced model that addresses other potential variables that could lead to an increase in tourist satisfaction and revisit intention. Variables, such as food quality, authentic atmosphere and entertainment programmes, may influence satisfaction and revisit intention, especially for return visitors. In modern times, all these aspects are central to new tourist concepts - those tourists eager of engage in new experiences that have an authentic local dimension and deviate from those that are generically globalized. Therefore, urban planners and tourism consumption producers have a great challenge - to redistribute and expand tourist areas in cities, adding new, interesting sites to their attraction portfolios while at the same not forgetting that the quality of life of residents cannot be adversely affected. Sustainability is the key and to achieve it, the participation of all stakeholders is required to govern and guide the process.

\section{References}


Ávila, R., \& Barrado, D. (2005). Nuevas tendencias en el desarrollo de destinos turísticos: marcos conceptuales y operativos para su planificación y gestión. Cuadernos de Economía, $15,27-43$

Axelsen, M., \& Swan, T. (2010). Designing festival experiences to influence visitor perceptions: The case of a wine and food festival. Journal of Travel Research, 49(4), 436450.

Barrado Timon, D. A. (2010). Big city and tourism in the post-industrial transition: new and old processes, new and old theories. The case study of metropolitan area of Madrid. Scripta Nova-Revista Electronica de Geografia y ciencias sociales, 14(317).

Bauder, M., \& Freytag, T. (2015). Visitor mobility in the city and the effects of travel preparation. Tourism Geographies, 17(5), 682-700.

Blázquez, M., \& Murray, I. (2011). Búnker playa-sol. Conflictos derivados de la construcción de enclaves de capital transnacional turístico español en El Caribe y Centroamérica. Scripta Nova, 15(368), 741-98

Byrne, B.M. (1998). Structural Equation Modelling with LISREL, PRELIS, and SIMPLIS: Basic concepts, applications, and programming. Mahwah, NJ: Lawrence Erlbaum. Björk, P., \& Kauppinen-Räisänen, H. (2013). Exploring the multi-dimensionality of travellers' culinary-gastronomic experiences. Current Issues in Tourism, 19(12), 1-21. Collins-Kreiner, N. (2016). The lifecycle of concepts: the case of 'Pilgrimage Tourism'. Tourism Geographies, 18(3), 322-334.

Crespi-Vallbona, M. C., \& Pérez, M. D. (2015). Tourism and Food Markets: A Typology of Food Markets from Case Studies of Barcelona and Madrid. Regions Magazine, 299(1), 15-17. Crespi-Vallbona, M. C., \& Pérez, M. D. (2016a). Los mercados de abastos y las ciudades turisticas. PASOS. Revista de Turismo y Patrimonio Cultural, 14(2), 401-416. 
Crespi-Vallbona, M. C., \& Pérez, M. D. (2016b). "Cultural heritage, leisure and citizenship: A case study of La Boqueria food market in Barcelona (Spain)", 62-74 in Vaugeois, N., Innovative Leisure Practices (Vol. 2): Cases as conduits between Theory and Practice. World Leisure Organization, Vancouver Island University.

Delgado, M. (2007). Antropología y turismo. Claves culturales y disciplinares, in Lagunas, D. Antropología y turismo. Claves culturales y disciplinares, México DF, UAEH: Plaza \& Valdés.

Donaher, E. (2012). Is Local More Expensive?.Research Paper. Ontario: University of Waterloo.http://www.wrfoodsystem.ca/files/www/MRP_FINAL_-_Evonne_Donaher.pdf Elkington, J. (1994), Towards sustainable corporation: Win-win-win business strategies for sustainable development, California Management Review, 36, 90-100.

Florida, R. (2009). Las ciudades creativas. Barcelona: Paidos.

Fornell, C., \& Larcker, D. F. (1981). Evaluating structural equation models with unobservable variables and measurement error. Journal of Marketing Research, 39-50. Frisvoll, S., Forbord, M., \& Blekesaune, A. (2016). An empirical investigation of tourists' consumption of local food in rural tourism. Scandinavian Journal of Hospitality and Tourism, 16(1), 76-93.

Glaeser, E. L., Kolko, J., \& Saiz, A. (2001). Consumer city. Journal of economic geography, $1(1), 27-50$.

Hair, J. F., Black, W. C., Babin, B. J., Anderson, R. E., \& Tatham, R. L. (2006). Multivariate data analysis 6th Edition. New Jersey: Pearson Education.

Hall, P. (1995). Towards a general urban theory. Cities in Competition: Productive and Sustainable Cities for the 21st Century, 3-31.

Hashimoto, A., \& Telfer, D. J. (2006). Selling Canadian culinary tourism: Branding the global and the regional product. Tourism Geographies, 8(1), 31-55. 
Hjalager, A. M. (2002). A typology of gastronomy tourism. In A. M. Hjalager, \& G. Richards (Ed.), Tourism and Gastronomy (pp. 21-35). London, UK: Routledge.

Hiebert, D., Rath, J., \& Vertovec, S. (2015). Urban markets and diversity: towards a research agenda. Ethnic and racial studies, 38(1), 5-21.

Kim, Y. G., Eves, A., \& Scarles, C. (2009). Building a model of local food consumption on trips and holidays: A grounded theory approach. International Journal of Hospitality Management, 28(3), 423-431.

Kim, Y. H., Kim, M., Goh, B. K., \& Antun, J. M. (2011). The role of money: the impact on food tourists' satisfaction and intention to revisit food events. Journal of Culinary Science \& Technology, 9(2), 85-98.

Kim, Y. H., Kim, M. C., Goh, B. K., \& Antun, J. (2010). A comparison between first-timers and repeaters at a food event. Journal of Culinary Science \& Technology, 7(4), 239-249. Kirillova, K., Fu, X., Lehto, X., \& Cai, L. (2014). What makes a destination beautiful? Dimensions of tourist aesthetic judgment. Tourism Management, 42, 282-293. La Vanguardia (23-08-2016; 09-02-2017; 12-02-2017). http://www.lavanguardia.com/.Accessed May 28, 2017 Lee, Y. K., Lee, C. K., Lee, S. K., \& Babin, B. J. (2008). Festivalscapes and patrons' emotions, satisfaction, and loyalty. Journal of Business Research, 61(1), 56-64.

Liu, Z. (2003), Sustainable Tourism Development: A Critique. Journal of Sustainable Tourism 11 (6): 459-475.

Malhotra, N. K. (2004). Marketing research: An applied orientation(4th ed.). Upper Saddle River, NJ: Prentice Hall.

Mason, M. C., \& Paggiaro, A. (2012). Investigating the role of festivalscape in culinary tourism: The case of food and wine events. Tourism Management, 33(6), 1329-1336. 
Mesura de Govern sobre Preservació i Millora del Mercat Municipal de la Boqueria, (2017), IMMB, Ajuntament de Barcelona.Working document, provided by hand.

Navarro, M. M., \& Iglesias, M. P. (2012). Desarrollo del turismo del vino desde da perspectiva de los productores: una primera aproximación al caso de Aragón-España. Estudios y perspectivas en turismo, 21(3), 585-603.

Nield, K., Kozak, M., \& LeGrys, G. (2000). The role of food service in tourist satisfaction. International Journal of Hospitality Management, 19(4), 375-384.

Okumus, F., Kock, G., Scantlebury, M. M., \& Okumus, B. (2013). Using local cuisines when promoting small Caribbean island destinations. Journal of Travel \& Tourism Marketing, $30(4), 410-429$.

Ozturk, U. A., \& Gogtas, H. (2016). Destination attributes, satisfaction, and the cruise visitor's intent to revisit and recommend. Tourism Geographies, 18(2), 194-212.

Paddin, C. (2012), A sustainable tourism planning model: Components and relationships. European Business Review 24(6): 510-518.

Petrick, J. F. (2004). First timers' and repeaters' perceived value. Journal of Travel Research, 43(1), 29-38

Pieniak, Z., Verbeke, W., Vanhonacker, F., Guerrero, L., \& Hersleth, M. (2009). Association between traditional food consumption and motives for food choice in six European countries. Appetite, 53(1), 101-108.

Pla Estratègic de la Ciutat, 2020. Ajuntament de Barcelona

Richards, G. (2007). Cultural tourism: Global and local perspectives. Binghamton, NY: Haworth Hospitality Press.

Richards, G. (2012). An overview of food and tourism trends and policies. In Food and the tourism experience: The OECD-Korea workshop (pp. 13-46). 
Smith, S., \& Costello, C. (2009). Culinary tourism: Satisfaction with a culinary event utilizing importance-performance grid analysis. Journal of Vacation Marketing, 15(2), 99110.

Steiger, J. H. (1990). Structural model evaluation and modification: An interval estimation approach. Multivariate behavioral research, 25(2), 173-180.

Steptoe, A., Pollard, T. M., \& Wardle, J. (1995). Development of a measure of the motives underlying the selection of food: the food choice questionnaire. Appetite, 25(3), 267-284. Silkes, C. A. (2012). Farmers' markets: A case for culinary tourism. Journal of culinary science \& technology, 10(4), 326-336.

Sims, R. (2009). Food, place and authenticity: local food and the sustainable tourism experience. Journal of Sustainable Tourism, 17(3), 321-336.

Taylor, J. P. (2001). Authenticity and sincerity in tourism. Annals of tourism research, 28(1), 7-26.

VVAA (2013), Herramienta del Sistema Europeo de Indicadores Turísticos para Destinos Sostenibles. UE: Comisión Europea, DG Empresa e Industria.

Wan, Y. K. P., \& Chan, S. H. J. (2013). Factors that affect the levels of tourists' satisfaction and loyalty towards food festivals: a case study of Macau. International journal of tourism research, 15(3), 226-240.

Wu, H. C., Wong, J. W. C., \& Cheng, C. C. (2014). An empirical study of behavioral intentions in the food festival: The case of Macau. Asia Pacific Journal of Tourism Research, 19(11), 1278-1305.

Yuan, J. J., \& Jang, S. S. (2007). The effects of quality and satisfaction on awareness and behavioral intentions: Exploring the role of a wine festival. Journal of Travel Research,46(3), $279-288$. 